\title{
Type A behavior pattern, risk propensity and empathy in young professionally active patients with bronchial asthma
}

\author{
Andrzej Witusik ${ }^{1}$, Piotr Kuna², Tadeusz Pietras ${ }^{3}$, Lukasz Mokros ${ }^{3}$ \\ ${ }^{1}$ Department of Psychology, Institute of Pedagogical Sciences, Faculty of Social Science, Piotrków Trybunalski Branch, \\ Jan Kochanowski University, Kielce, Poland \\ 2Department of Internal Medicine, Asthma and Allergy, Medical University of Lodz, Lodz, Poland \\ ${ }^{3}$ Department of Clinical Pharmacology, Medical University of Lodz, Lodz, Poland
}

Adv Dermatol Allergol 2018; XXXV (6): 587-591

DOI: https://doi.org/10.5114/ada.2018.77610

\begin{abstract}
Introduction: Type A behavior pattern is an important risk factor for cardiovascular diseases. It is a learned way to respond to stress. The capability of empathy and impulsiveness is an important element of functioning of the human being.

Aim: To assess the degree of bronchial asthma control in the context of the intensity of type A pattern of behavior, Impulsivity, Risk Propensity and Empathy.

Material and methods: The study involved examination of 150 subjects, including 111 with asthma of different degrees of control, all of whom were young, professionally active people. Two validated questionnaires (IVE Impulsivity Questionnaire and Type A Scale) were used to assess the correlation between the degrees of asthma control and type A behavior pattern, Empathy, Impulsivity and Risk Propensity.

Results: The level of type A behavior pattern was significantly higher in the subjects with poorly controlled asthma as compared with those with partially controlled and well-controlled asthma and with healthy subjects. Impulsivity and Risk Propensity were higher in the group with poorly controlled asthma compared with the other analyzed groups. Empathy was lower in the group with poorly controlled asthma than in the other analyzed groups. There was no difference in the intensity of the analyzed mental variables between persons with partially controlled and well-controlled asthma and people without bronchial asthma.

Conclusions: Poor control of asthma may be associated with type A behavior pattern and high impulsivity and risk propensity.
\end{abstract}

Key words: asthma control, type A behavior pattern, impulsiveness, empathy, risk propensity.

\section{Introduction}

Bronchial asthma develops in approx. $5 \%$ of the adult population most often underlain by allergic, eosinophilic bronchitis [1, 2]. Inflammatory mediators secreted by the inflammatory cells and innate tendency to bronchial hyperactivity lead to attacks of airflow obstruction, accompanied by severe dyspnea [3]. Stress and mental factors can induce fits of breathlessness in the course of bronchial asthma [4]. The relationship between the perceived stress levels and induction of the attacks of dyspnea is not completely understood. Both stress-related hyperventilation with cold air and various inflammatory mediators secreted during stress and anxiety attacks are taken into consideration [4].
Stress is a modulator of dyspnea attacks in the course of bronchial asthma, which means that asthma is a psychosomatic disorder [5, 6]. Therefore, the personality and temperamental variables may have a certain impact on the clinical presentation of bronchial asthma, as demonstrated repeatedly in our publications [5]. On the other hand, the tendency to dyspnea attacks itself, a sense of danger and anxiety accompanying the attacks, and medications acting on the receptors in the central nervous system (e.g. theophylline) can in some way affect the development of temperament and personality $[5,6]$.

The innate characteristics of the temperament and the strong influence of social learning, develop a style of behavior. The style of behavior is understood as a set

Address for correspondence: Lukasz Mokros, Department of Clinical Pharmacology, Medical University of Lodz, 22 Kopcińskiego St, 90-153 Lodz, Poland, phone: +48 4267875 05, e-mail: lukasz.mokros@umed.lodz.pl

Received: 28.08.2017, accepted: 8.10.2017. 
of human behavioral features, which is a product of biological factors, as well as social learning [7, 8]. One of the known anti-health behavior styles is the so-called type A pattern of behavior, predisposing to the development of cardiovascular diseases, in particular coronary heart disease $[9,10]$. This construct was developed by Friedman and Rosenman. It is defined as an anti-health lifestyle behavior, resulting from the interaction between the personality factors and the imposition of social learning processes on the temperamental traits. The type A pattern of behavior means continuous striving to achieve as many goals as possible in a short period of time. Anger, rivalry and hostility are considered its basic elements $[9,10]$. Originally, that pattern of behavior was associated with ischemic heart disease. Subsequently, it was noted to be a non-specific risk factor for many diseases, including bronchial asthma exacerbations [9, 10]. The question arises as to whether the propensity for aggression and annoyance typical of the A behavior pattern may result in dyspnea attacks and may be associated with the control of asthma in bronchial asthma patients [9]. Impulsivity, risk propensity and empathy are important psychological variables moderating the response to stress [11]. It should be assumed that the mental stressmoderating variables may correlate with the degree of control of bronchial asthma and the behavior pattern.

\section{Aim}

The aim of the research was to assess the degree of bronchial asthma control in young professionally active people in the context of the intensity of type A pattern of behavior, impulsivity, risk propensity and empathy.

\section{Material and methods}

The research was conducted on a group of 111 subjects with bronchial asthma aged 20-50 years, patients of the outpatient asthma treatment department of Norbert Barlicki Memorial University Clinical Hospital No 1. The control group consisted of 39 healthy individuals. Patients with cancer, chronic obstructive pulmonary disease, systemic connective tissue diseases, past acute coronary episode during the last 6 months, and those experiencing intensive stress due to mourning, surgery or job loss were excluded from the study. Subjects above 50 years of age were also excluded. The degree of bronchial asthma control was determined using the Asthma Control Test [12, 13]. In the Asthma Control Test consisting of five questions, the score of 25 points was regarded as good control of asthma, the result of 20-24 points - as partial control and 20 points or less - as poor control. Poor control of asthma was diagnosed in 31 subjects, partial control in 27, and good control in 60. The studied groups did not differ significantly in the demographic variables, as presented in Table 1. The pattern of behavior A was measured using Type A scale adapted to Polish by Juczyński [14]. This is a unidimensional questionnaire in which the result approximating one corresponds to pattern A, whereas a near-zero result corresponds to behavior pattern B. To measure impulsivity, risk propensity and empathy, the IVE Impulsivity Questionnaire [11] was used. This questionnaire measures three personality variables - empathy, impulsiveness and venturesomeness (propensity to risk).

\section{Statistical analysis}

Statistical analysis was performed using Statistica 13 PL software. Mean values and standard deviations were used to characterize the continuous variables. Due to the sample size $(N=150)$, limit theorems were used and verification of the hypothesis of normality distribution of continuous variables was not conducted. The hypothesis of homogeneity of the variance of continuous variables in groups identified on the basis of the degree of asthma control was verified using Levene test. Intergroup comparisons were performed using analysis of variance (F test) with a post-hoc Tukey test for groups of varying size. The relationship between two continuous variables

Table 1. Comparison of age and scores in Type A Behavior Pattern scales and IVE (Impulsiveness, Venturesomeness, Empathy) scales among groups determined by the level of asthma control in the analyzed sample

\begin{tabular}{|c|c|c|c|c|c|c|c|c|c|c|}
\hline \multirow[t]{3}{*}{ Parameter } & \multirow{2}{*}{\multicolumn{2}{|c|}{$\begin{array}{l}\text { Healthy subjects } \\
\qquad(n=39)\end{array}$}} & \multicolumn{6}{|c|}{ Level of asthma control } & \multirow[t]{3}{*}{$F$} & \multirow[t]{3}{*}{$P$-value } \\
\hline & & & \multicolumn{2}{|c|}{ Good $(n=52)$} & \multicolumn{2}{|c|}{ Partial $(n=28)$} & \multicolumn{2}{|c|}{ Poor $(n=31)$} & & \\
\hline & $M$ & SD & $M$ & SD & M & SD & $M$ & SD & & \\
\hline Age & 31.69 & 9.56 & 32.63 & 9.47 & 32.04 & 7.96 & 35.77 & 8.85 & 1.356 & 0.259 \\
\hline $\begin{array}{l}\text { Type A behavior } \\
\text { pattern }\end{array}$ & $0.39^{\star}$ & 0.14 & $0.41^{*}$ & 0.14 & $0.45^{\star}$ & 0.12 & 0.63 & 0.15 & 19.995 & $<0.001$ \\
\hline Empathy & $12.46^{\star}$ & 2.88 & $12.63^{*}$ & 2.47 & $12.14^{\star}$ & 2.90 & 7.77 & 2.06 & 27.043 & $<0.001$ \\
\hline Risk Propensity & $7.33^{*}$ & 3.36 & $7.52^{*}$ & 2.56 & $7.71^{*}$ & 1.74 & 12.03 & 2.68 & 23.297 & $<0.001$ \\
\hline Impulsiveness & $8.00^{\star}$ & 2.62 & $7.40^{*}$ & 2.65 & $8.68^{\star}$ & 3.35 & 13.42 & 3.29 & 30.445 & $<0.001$ \\
\hline
\end{tabular}

$M$ - mean, SD - standard deviation, F-F statistics, $p$ - probability in the F test, ${ }^{*} p<0.001$ vs. poorly controlled asthma in post-hoc Tukey test. 
was evaluated using the Pearson correlation coefficient. The assumed level of statistical significance was $\alpha=0.05$.

\section{Results}

The intensity of type A behavior pattern was demonstrated to be significantly higher in the subjects with poorly controlled asthma as compared with those with partially controlled and well-controlled asthma and with healthy subjects (Table 1). Also the dimensions of Impulsivity and Risk Propensity were higher in the group with poorly controlled asthma compared with the other analyzed groups. Empathy was lower in the group with poorly controlled asthma than in the other analyzed groups. There was no difference in the intensity of the analyzed mental variables between persons with partially controlled and well-controlled asthma and people without bronchial asthma (Table 1).

The level of the Risk Propensity dimension correlated positively with the intensity of Impulsivity and a tendency to type A behavior pattern (Table 2). In contrast, the level of Empathy correlated negatively with other mental variables (Table 2 ).

The analyzed variables did not differ according to sex of the examined subjects (Table 3). There was also no correlation between the age of the examinees and the mental variables (Table 2).

\section{Discussion}

Subjects with poor control of bronchial asthma are characterized by higher intensity of type A Behavior Pattern, Impulsiveness and Risk Propensity. The above may allow to characterize such individuals, with due caution, as impulsive, emotionally unbalanced, willing to take risk, with a low level of empathy. From the standpoint of differential psychology, such a person is impulsive and undertaking risky behaviors, both externalized and internalized [7]. Such personal characteristics are close to the concept of a "difficult temperament" the existence of which was noted by Strelau [15]. An impulsive person, willing to take risks can find it difficult to control attacks of bron-
Table 2. Pearson's correlation coefficients between the selected continuous variables

\begin{tabular}{lcccc}
\hline Parameter & Age & $\begin{array}{c}\text { Type A } \\
\text { behavior }\end{array}$ & Empathy & $\begin{array}{c}\text { Risk } \\
\text { Propensity }\end{array}$ \\
\hline Type A behavior & 0.032 & & & \\
\hline Empathy & -0.144 & $-0.301^{*}$ & & \\
\hline Risk Propensity & 0.079 & $0.480^{*}$ & $-0.421^{*}$ & \\
\hline Impulsiveness & 0.089 & $0.397^{*}$ & $-0.390^{*}$ & $0.593^{*}$ \\
\hline
\end{tabular}

${ }^{*} p<0.001$.

chial asthma and to cope with difficult situations, which may result in poor asthma control [16]. Strong emotional stimulation accompanying high impulsivity, propensity to risk, and high predisposition to present type A pattern of behavior strongly stimulates the central nervous system, and this triggers hyperventilation and attacks of dyspnea due to bronchial hyperactivity typical of asthma [16, 17]. Type A behavior pattern is characterized by continuous tension, the tendency to compete, the need for achievement and propensity to risk in work-related situations [18]. It has been shown to be a risk factor for development of ischemic heart disease as a way of the subject's response to stress [19]. The discovery of the importance of type A behavior pattern for the development of ischemic heart disease has become the basis for the development of psychosomatics as a branch of science. Individuals with type A behavior pattern pay attention to the aspects of the job situation which involve competition, hostility or require immediate response [20]. Such persons in stressful situations trigger physiological reactions of the body such as increased blood pressure, turbulent blood flow, increase in the level of catecholamines, and hyperventilation [20]. This is clearly associated with the risk of cardiovascular diseases. Hyperventilation (in combination with bronchial hyperactivity caused by chronic eosinophilic inflammation and genetic factors) promotes uncontrolled attacks of dyspnea $[20,21]$. Stimulation with cold air during stress-related hyperventilation favors dyspnea attacks in the course of bronchial asthma. Rivalry may also mean a low level of

Table 3. Comparison of age and scores in Type A Behavior Pattern scales and IVE (Impulsiveness, Venturesomeness, Empathy) according to sex in the analyzed sample

\begin{tabular}{|c|c|c|c|c|c|c|}
\hline \multirow[t]{2}{*}{ Parameter } & \multicolumn{2}{|c|}{ Men $(n=75)$} & \multicolumn{2}{|c|}{ Women $(n=75)$} & \multirow[t]{2}{*}{$t$} & \multirow[t]{2}{*}{$P$-value } \\
\hline & $M$ & SD & $M$ & SD & & \\
\hline Age & 32.55 & 9.08 & 33.31 & 9.24 & -0.508 & 0.612 \\
\hline Type A behavior & 0.47 & 0.15 & 0.45 & 0.17 & 0.838 & 0.404 \\
\hline Empathy & 11.09 & 3.15 & 11,89 & 3.22 & -1.538 & 0.126 \\
\hline Risk Propensity & 8.47 & 3.13 & 8.41 & 3.37 & 0.100 & 0.920 \\
\hline Impulsiveness & 9.07 & 3.76 & 9.01 & 3.63 & 0.088 & 0.930 \\
\hline
\end{tabular}

$M$ - mean, SD - standard deviation, $t$ - Student-t statistics, $p$ - probability in Student- $t$ test. 
empathy, which has been shown in our studies. It is also conceivable that a low level of empathy means inability to seek help of the social environment in the event of a dyspnea attack of breathlessness in bronchial asthma, which can contribute to poor asthma control. The above remains only our hypothesis that requires empirical verification.

Type A pattern of behavior, and Propensity to Risk, as well as to some extent Impulsivity, are the characteristics developing as a result of the interaction of temperamental personality factors and social learning $[7,15]$. The temperamental factors are partially genetically conditioned [22]. In our previous studies, we have shown that certain polymorphic variants of the gene coding the glucocorticoid receptor are important in determination of the temperament structure in subjects with bronchial asthma [16]. Possibly, poor control of asthma may be linked to the same genetic predispositions as the tendency to impulsive reactions, propensity to risk and low empathy. Poorly controlled asthma does not have to be the result of a particular structure of personality and behavior, it can also partly result from the common genetic predispositions. This hypothesis, however, requires confirmation by genetic research on the polymorphic variants of the selected genes in the context of psychological variables, conducted on large samples. Such studies have been conducted on the relationship between the structure of temperament and the polymorphic variants of some of the genes encoding the proteins responsible for transport of catecholamines in the brain [15]. Conclusions based on the results of this type of research should be formulated with caution because of their low repeatability.

A shortcoming of our research is the lack of determination of the connection between the analyzed variables, satisfaction with work and job position, since only professionally active people working on a regular basis were studied. Our work should be treated only as a pilot study and thus it would be advisable to repeat the study on a larger group. On the other hand, a good credibility of our research is supported by the fact that the results obtained by us in the group of healthy subjects with respect to the level of Empathy, Impulsiveness and Risk Propensity are similar to those obtained by the authors of standardization of the Polish version of the psychometric tool [11]. The values obtained by us for the group of healthy subjects in the aforementioned scales fall within the range of the fifth and sixth standard ten, i.e. within the average range [11]. However, it is difficult to interpret the results in terms of the presented type $A$ behavior pattern in view of the lack of published standards for type A Scale test. An average score of 0.39 in the healthy group indicates rather the predominance of type B behavior pattern. In the group with poorly controlled asthma, the result of 0.63 suggests the predominance of type A behavior pattern.

In a monograph published by our team in 2011, type A behavior pattern was studied using the original test de- veloped by Jenkins and Rosenman and Zyzanski in the version translated by Wrześniewski with the permission of the authors [23]. No differences between asthma patients and healthy subjects in the intensity of behavior pattern dimension were observed then. However, the studied group included mainly patients with mild, wellcontrolled asthma. On the other hand, an analysis of three factors distinguished in that test - the $\mathrm{H}$ factor (denoting involvement in a specific action), the J factor (denoting involvement in professional work) and the $\mathrm{S}$ factor (measuring the dynamics of behavior) would be interesting [23]. These factors characterize well the importance of type A behavior pattern in the professional activities performed by a person, including a person with bronchial asthma. The type A Scale test developed by Juczyński does not distinguish these factors, it only informs about the position of the tested subject in the continuum between A and B patterns of behavior. In our opinion, this test is less useful in work psychology and clinical psychology than the original, three-factor tool developed by the creators of the concept of type $A$ behavior pattern.

It would also be interesting to determine the relationship between the psychological profile of the patient and other variables characterizing the course of poorly controlled asthma, such as the cell phenotype of asthma [24], the presence of steroid resistance and the used medication, or a type of the accompanying allergy [25]. A group of 31 patients with poorly controlled asthma is too small to attempt such analyses. It should also be kept in mind that our research is only correlative in character. Therefore, it does not mean that any person with poorly controlled asthma is impulsive, willing to take risks and not very empathic. Such understanding of population surveys would foster stigmatization of patients with poorly controlled asthma [26]. The social aspect of interpretation of the results of our research should rather attract attention to the possibilities of psychotherapeutic work with this group of patients, oriented at improving empathy, reducing impulsiveness and penchant for unpredictable actions, to be provided as a method of support for people with poorly controlled asthma [27, 28]. However, the effectiveness of these methods in the treatment of poorly controlled asthma requires verification.

The lack of statistically significant correlation between the analyzed variables and age reflects the wellknown fact that the structure of the temperament does not change significantly in humans during the period of professional activity between 19 and 50 years of age [7]. Temperament and personality are relatively stable dimensions in an adult [7]. The results might be different if the analyzed variables were studied during adolescence or in elderly subjects [7]. In the case of correct treatment, the severity of asthma and indirectly the level of its control are also relatively stable during the period of professional activity [29]. Only advanced aging weakens 
the immune reactivity in allergic diseases [30], affecting likewise the functioning of the central nervous system and the psychological variables [31].

\section{Conclusions}

People with badly controlled bronchial asthma were characterized by a higher intensity of type A pattern of behavior, impulsivity and propensity to risk, and lower intensity of empathy, than people with partially controlled and well-controlled asthma and healthy subjects. The severity of impulsiveness and propensity to risk, and type A pattern of behavior correlate positively with one another. The level of empathy correlates negatively with the other variables.

\section{Conflict of interest}

The authors declare no conflict of interest.

\section{References}

1. Panek M, Mokros $\measuredangle$, Pietras T, et al. The epidemiology of asthma and its comorbidities in Poland: health problems of patients with severe asthma as evidenced in the Province of Lodz. Respir Med 2016; 112: 31-8.

2. Thiriou D, Morianos I, Xanthou G. Innate immunity as the orchestrator of allergic airway inflammation and resolution in asthma. Int Immunopharmacol 2017; 48: 43-54.

3. Panek M, Pietras T, Szemraj J, et al. Identification and association of TGFbeta-1 expression in patients with asthma in a Polish population - Lodz metropolitan area study. Int J Biochem Mol Biol 2013; 4: 67-74.

4. Booster GD, Oland AA, Bender BG. Psychosocial factors in severe pediatric asthma. Immunol Allergy Clin North Am 2016; 36: 449-60.

5. Panek M, Kuna P, Witusik A, et al. Temperament and stress coping styles in bronchial asthma patients. Postep Dermatol Alergol 2016; 33: 469-74.

6. Pietras T, Witusik A, Panek M, et al. Anxiety, depression and methods of stress coping in patients with nicotine dependence syndrome. Med Sci Monit 2011; 17: CR272-6.

7. Strelau J. Individual differences. History - determinants application [Polish]. Scholar Scientific Publications, Warsaw School of Social Psychology, Warsaw 2015.

8. Ohno I. Neuropsychiatry phenotype in asthma: psychological stress-induced alterations of the neuroendocrine-immune system in allergic airway inflammation. Allergol Int 2017; 66S: S2-8.

9. Rosenman RH. Do environmental effects on human emotions cause cardiovascular disorders? Acta Physiol Scand Suppl 1997; 640: 133-6.

10. Richards SH, Anderson L, Jenkinson CE, et al. Psychological interventions for coronary heart disease. Cochrane Database Syst Rev 2017; 4: CD002902.

11. Jaworowska A. IVE Impulsivity Questionnaire. Impulsiveness. Venturesomeness. Empathy. Polish Standarization [Polish]. Psychological Tests Laboratory of the Polish Psychological Association, Warsaw 2011.

12. www.ginasthma.org/2016

13. Juniper EF, O'Byrne PM, Guyatt GH, et al. Development and validation of a questionnaire to measure asthma control. Eur Respir J 1999; 14: 902-7.
14. Juczyński Z. Measurement tools in health promotion and psychology [Polish]. Psychological Tests Laboratory of the Polish Psychological Association, Warsaw 209.

15. Strelau J. Psychology of temperament. Wydawnictwo Naukowe PWN, Warsaw 2012.

16. Panek M, Pietras T, Witusik A, et al. Identification and association of relationships between selected personal and environmental factors and formal components of temperament and strategies of coping with stress in asthmatic patients. Physiol Behav 2015; 149: 269-78.

17. Lehrer PM. Emotionally triggered asthma: a review of research literature and some hypotheses for self-regulation therapies. Appl Psychophysiol Biofeedback 1998; 23: 13-41.

18. Yoshimasu K; Fukuoka Heart Study Group. Correlation of type A behavior pattern and job-related psychosocial factors to nonfatal myocardial infarction: a case-control study of Japanese male workers and women. Psychosom Med 2001; 63: 797-804.

19. Haskell WL. Cardiovascular disease prevention and lifestyle interventions: effectiveness and efficacy. J Cardiovasc Nurs 2003; 18: 245-55.

20. Ścigała E. Cognitive predispositions for coronary heart disease and myocardial infarction [Polish]. Adam Mickiewicz University Press, Poznan 1993.

21. Lloyd CM, Saglani S. Development of allergic immunity in early life. Immunol Rev 2017; 278: 101-15.

22. Oniszczenko W, Rybakowski JK, Dragan Wt, et al. The ADH gene cluster SNP rs1789891 and temperamental dimensions in patients with alcohol dependence and affective disorders. Scand J Psychol 2015; 56: 420-7.

23. Witusik A, Pietras T. Personality-related and behavioral factors in clinical presentation of bronchial asthma. Naukowe Wydawnictwo Piotrkowskie, Piotrków Trybunalski 2011.

24. Terl M, Sedlák V, Cap P, et al. Asthma management: a new phenotype-based approach using presence of eosinophilia and allergy. Allergy 2017; 72: 1279-87.

25. Rodriguez JM, Monsalves-Alvarez M, Henriquez S, et al. Glucocorticoid resistance in chronic diseases. Steroids 2016; 115: 182-92.

26. Rose S, Paul C, Boyes A, et al. Stigma-related experiences in non-communicable respiratory diseases: a systematic review. Chron Respir Dis 2017; 14: 199-216.

27. Yorke J, Fleming S, Shuldham C, et al. Nonpharmacological interventions aimed at modifying health and behavioural outcomes for adults with asthma: a critical review. Clin Exp Allergy 2015; 45: 1750-64.

28. Mosnaim GS, Pappalardo AA, Resnick SE, et al. Behavioral interventions to improve asthma outcomes for adolescents: a systematic review. J Allergy Clin Immunol Pract 2016; 4: 130-41.

29. Droszcz W, Grzanka A. Asthma in adolescents and adults [Polish]. PZWL Medical Publishing, Warsaw 2010.

30. Benfante A, Scichilone N. The geriatric asthma: pitfalls and challenges. Asthma Res Pract 2016; 2: 2.

31. Blasimme A. Physical frailty, sarcopenia, and the enablement of autonomy: philosophical issues in geriatric medicine. Aging Clin Exp Res 2017; 29: 59-63. 